\title{
Bimetallic sulfide based on various carbon materials for supercapacitors
}

\author{
YaoChen Song ${ }^{1,2}$, Xinran $\mathrm{Li}^{1}$, Junchao Wang ${ }^{1}$, Mengqiang $\mathrm{Wu}^{1 *}$, Jiaxuan Liao ${ }^{1,2, *}$ \\ ${ }^{1}$ School of Materials and Energy, University of Electronic Science and Technology of China, Chengdu 611731, P.R. China. \\ ${ }^{2}$ Yangtze Delta Region Institute (Quzhou), University of Electronic Science and Technology of China, Quzhou, Zhejiang \\ 324000, China
}

\begin{abstract}
The $\mathrm{NiCo}_{2} \mathrm{~S}_{4} / \mathrm{C}$ hybrid material was successfully prepared by a simple one-step hydrothermal method. Carbon composite increases the specific surface area of the material and provides more ion attachment points during the electrochemical process. Conducive to the ion transportation and transfer, the composition of carbon material greatly improves the conductivity of the hybrid material. Electric doublelayer capacitor materials can accept transferred ions faster than pseudocapacitor materials, enable the hybrid materials better adapt to intensity current changes. Compared with a single carbon material or a pseudocapacitance material, it has a higher specific capacity. This discovery is of great significance to the research of pseudocapacitive materials and supercapacitors.
\end{abstract}

\section{Introduction}

Supercapacitors have become a research hotspot in the field of energy storage in recent years because of their high-power density, stable long cycle life, low price, and simple production. In order to obtain higher energy density, it is very urgent to develop pseudocapacitance electrode materials with higher specific capacity. Studies have shown that transition metal oxides and sulfides based on multivalent ions such as $\mathrm{Co}$ [1], $\mathrm{Ni}$ [2], $\mathrm{Mn}[3,4]$, etc., have an outstanding performance, specifically in capacity. However, such pseudocapacitance materials are often unsatisfactory in terms of cycle performance and rate performance. Therefore, preparing an electrode material that integrates high energy density, high rate performance and high cycle performance has become a major issue.

Studies have shown that, compared with single metal sulfides, divalent metal sulfides (single metal sulfides with two different valence states or sulfides of different metals) can be promoted due to the synergistic promotion of two metal ions. Significantly improve the conductivity of the material, thereby improving the material's specific capacity, rate performance and cycle stability [5]. Li Y et al. added $\mathrm{Co}^{2+}$ in order to improve the cycle performance of a single nickel sulfide, and the results showed that its cycle life has been greatly enhanced [6]. Cao Y Q et al. increased the conversion efficiency of nickel by adding nickel hydroxide to $\mathrm{Ni}_{3} \mathrm{~S}_{2}$ to increase the concentration difference [7]. Studies have shown that $\mathrm{Ni}_{3} \mathrm{~S}_{2}$ transforms into porous $\mathrm{Ni}(\mathrm{OH})_{2}$ during charge and discharge, which greatly improves the cycle stability of the material [8]. In addition, the doping of high-conductivity carbon material can also greatly increase the electrical conductivity of the electrode material. Meanwhile, improve the overall electrochemical performance of the electrode material. Delong Li et al. used CNTs as the conductive network of $\mathrm{NiCo}_{2} \mathrm{~S}_{4}$, and successfully prepared a hexagonal nanoplate structure $\mathrm{NiCo}_{2} \mathrm{~S}_{4} / \mathrm{CNTs}$ composite material by hydrothermal method. This three-dimensional structure prevented the agglomeration of carbon nanotubes and $\mathrm{NiCo}_{2} \mathrm{~S}_{4}$. It has excellent supercapacitor performance, such as specific capacitance as high as 1537 F/g (@1 A/g) [9]. Fangping Wang et al. obtained graphene nanosheet sandwich structure $\mathrm{NiCo}_{2} \mathrm{~S}_{4} / \mathrm{rGO}$ composite material by compounding $\mathrm{rGO}$ in a one-step hydrothermal method. This structure prevents the reassembly of the reduced graphene oxide, provides a smooth channel for the electrolyte to enter, promotes the transport of ions, and obtains better electrochemical performance [10].

The manuscript uses a one-step hydrothermal method to prepare bimetallic nano- $\mathrm{NiCo}_{2} \mathrm{~S}_{4} / \mathrm{C}$ composite materials. The specific components of the materials are determined by XRD, XPS and other related technologies. The microstructure and surface morphology of the prepared materials are analyzed by SEM, and the three electrodes are tested. In the experiment, the structure, morphology and electrochemical performance of the sulfide are adjusted by adjusting the type and quality of the carbon source, so as to determine the optimal process parameters to achieve high specific capacity, good rate characteristics and excellent cycle stability. After testing, analysis and comparison, the electrochemical performance of $\mathrm{NiCo}_{2} \mathrm{~S}_{4}$ has been significantly improved after forming a composite material with carbon. Among them, it has the highest specific capacity after being

* Corresponding author: jxliao@uestc.edu.cn (J. Liao); mwu@uestc.edu.cn (M. Wu). 
composited with high-conductivity carbonylated carbon nanotubes, and it reaches $1939.12 \mathrm{~F} / \mathrm{g}$ under the current density of $1 \mathrm{~A} / \mathrm{g}$, and can still maintain excellent performance under even higher current density.

\section{Experimental Section}

The $\mathrm{NiCo}_{2} \mathrm{~S}_{4}$ material was prepared by a one-step hydrothermal method. $1.7448 \mathrm{~g} \mathrm{Ni}\left(\mathrm{NO}_{3}\right)_{2} \cdot 6 \mathrm{H}_{2} \mathrm{O}, 3.4926$ g $\mathrm{Co}\left(\mathrm{NO}_{3}\right)_{2} \cdot 6 \mathrm{H}_{2} \mathrm{O}, 0.1 \mathrm{~g}$ polyvinylpyrrolidone (PVP$\mathrm{K} 30$ ), $1.8 \mathrm{~g}$ thioacetamide and a certain amount of carbon materials were sequentially added to a mixed solution of ethylene glycol and deionized water (volume $1: 3$ ). After stirring, the solution was hydrothermally reacted at $150^{\circ} \mathrm{C}$ for 5 hours, filtered and cleaned to obtain $\mathrm{NiCo}_{2} \mathrm{~S}_{4} / \mathrm{C}$. In this paper, six kinds of carbon sources are selected for compounding with NiCo2S4 materials. They are activated carbon (NCS-AC), graphene oxide (NCS-GO), hydroxylated short carbon nanotubes (NCS-s-OH), carbonylated short carbon nanotubes (NCS-s-COOH), high conductive Hydroxylated carbon nanotubes (NCS-h-OH), high conductive carbonylated carbon nanotubes (NCS-h$\mathrm{COOH})$.

All the electrode materials in this article are tested under a three-electrode system. The working electrode is a self-prepared active electrode material, the counter electrode is a Pt electrode, the reference electrode is an $\mathrm{Ag} / \mathrm{AgCl}$ electrode, and the electrolyte is $3 \mathrm{M} \mathrm{KOH}$ solution. The instruments used for material characterization are ASAP-2010 physical adsorption analyzer, JSM-IT500 scanning electron microscope, and D8 DISCVER X-ray diffraction analyzer.

\section{Results and discussion}

Fig. 1a shows the XRD patterns of electrode materials prepared by $\mathrm{NiCo}_{2} \mathrm{~S}_{4}$ composited with different carbon sources. The diffraction peaks appear at $2 \theta=26.5^{\circ}, 31.7^{\circ}$, $38.1^{\circ}, 50.3^{\circ}$ and $55.1^{\circ}$. Compared with the standard PDF card, the peak position is almost completely matched, indicating that the material generated by the hydrothermal method is still $\mathrm{NiCO}_{2} \mathrm{~S}_{4}$ after being compounded with the carbon source. Due to the low carbon source content, the diffraction peaks cannot be clearly identified, so it is difficult to clearly see the diffraction peaks of $\mathrm{C}$ in the figure. Comparing the above six curves, we can see subtle differences. The main reason may be the presence of carbon materials in the solution, which makes $\mathrm{NiCo}_{2} \mathrm{~S}_{4}$ crystal grains grow along certain crystal planes with a preferential orientation, so that there are some diffraction peaks in $\mathrm{XRD}$. The higher the intensity, the peak intensity is not completely consistent.

Fig. $1 \mathrm{~b}$ shows the $\mathrm{N}_{2}$ adsorption and desorption curves of different $\mathrm{NiCO}_{2} \mathrm{~S}_{4} / \mathrm{C}$ composite materials. NCS-AC, NCS-GO, NCS-s-OH, NCS-s-COOH, NCS-h$\mathrm{OH}$, the specific surface area of NCS-h-COOH is $105.744,9.736,18.457,16.757,23.003,32.792 \mathrm{~m}^{2} / \mathrm{g}$. NCS-AC has the largest specific surface area, followed by NCS-h-COOH, and NCS-GO has the smallest specific surface area. Fig. 1c shows the pore size distribution of different $\mathrm{NiCo}_{2} \mathrm{~S}_{4} / \mathrm{C}$ composites. Through calculation, the most probable pores are 2.4932, 2.5297, 2.1690, 2.5170, 2.5034 and $2.5237 \mathrm{~nm}$.
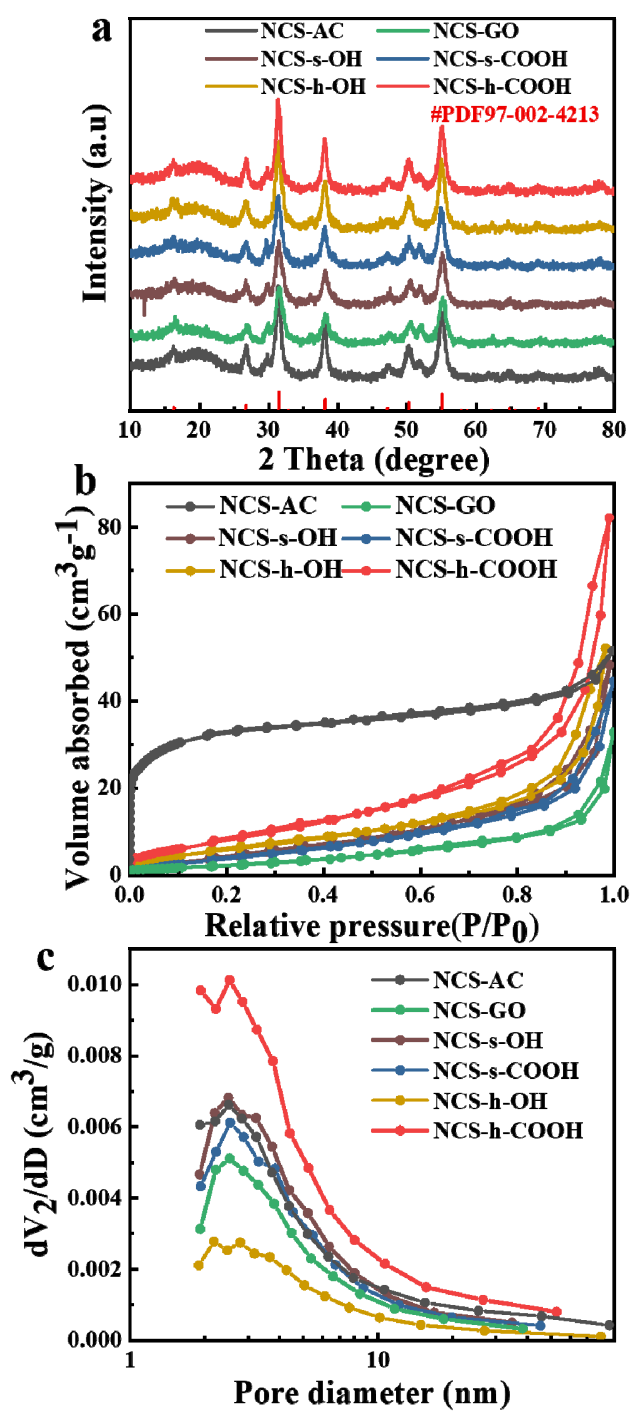

Fig. 1. XRD patterns (a), $\mathrm{N}_{2}$ adsorption and desorption curves (b) and pore size distribution (c) of different $\mathrm{NiCo}_{2} \mathrm{~S}_{4} / \mathrm{C}$ composite materials

Fig. 2a-d shows the SEM images of different $\mathrm{NiCo}_{2} \mathrm{~S}_{4} / \mathrm{C}$ composite materials. It can be seen from the Fig. that the generated $\mathrm{NiCo}_{2} \mathrm{~S}_{4}$ exhibits a stacked nanosheet structure. Fig. 2a-d shows that there are basically no traces of carbon nanotubes. The carbon nanotubes with hydroxyl or carboxyl functional groups are very short (20-30nm) and completely wrapped by the hydrothermally $\mathrm{NiCo}_{2} \mathrm{~S}_{4}$ material, so that almost only the structure of the external $\mathrm{NiCo}_{2} \mathrm{~S}_{4}$ sheet material can be observed. Fig. 2c can clearly see the presence of carbon nanotubes, but the interweaving is not very obvious, and only a few materials are attached to the surface of the carbon nanotubes. Fig. 2d can clearly see the fusion of carbon nanotubes and $\mathrm{NiCo}_{2} \mathrm{~S}_{4}$ materials. Carbon tubes are used as the main carrier to support the growth of the material. This may be attributed to the fact that the carboxylation of carbon nanotubes is more beneficial than the hydroxylation treatment. $\mathrm{NiCo}_{2} \mathrm{~S}_{4}$ grains are 
adsorbed on the surface of the carbon tube, thus showing a better composite effect. Fig. 2e is the SEM of the $\mathrm{NiCo}_{2} \mathrm{~S}_{4}$ composite graphene material. It can be seen that the graphene maintains the original sheet structure. The material is distributed on the graphene surface and embedded in the gaps and three-dimensional cracks of the sheet. The overall appearance is still a stacked nanosheet layer. Fig. $2 \mathrm{f}$ is the SEM of the $\mathrm{NiCo}_{2} \mathrm{~S}_{4}$ composite activated carbon material. The activated carbon in the picture shows a spherical shape. $\mathrm{NiCo}_{2} \mathrm{~S}_{4}$ grows on the spherical shape, but a large part of the spherical area is not covered by the material, indicating that its growth is not uniform. In general, the morphology of the $\mathrm{NiCo}_{2} \mathrm{~S}_{4} / \mathrm{C}$ composite material is indeed affected by the composite carbon source.

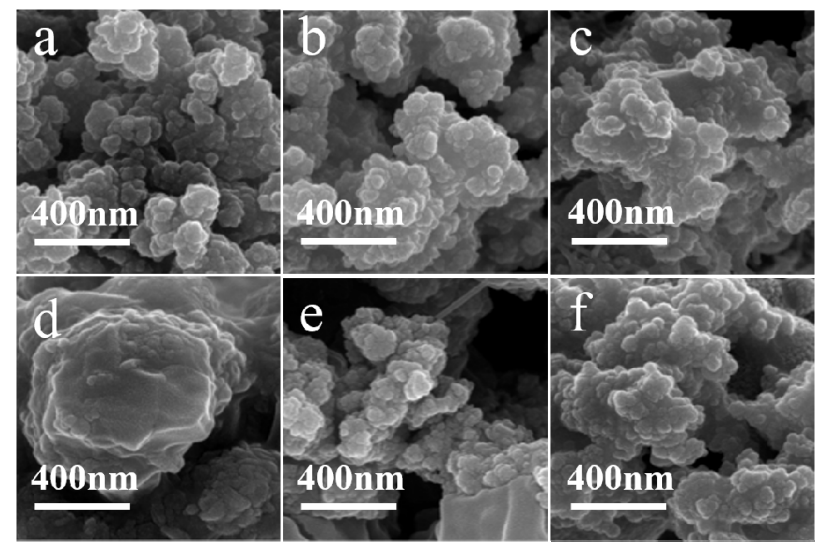

Fig. 2. The SEM images of different $\mathrm{NiCo}_{2} \mathrm{~S}_{4} / \mathrm{C}$ composite materials

Fig. 3 shows the cyclic voltammetry curves of different $\mathrm{NiCo}_{2} \mathrm{~S}_{4} / \mathrm{C}$ composite materials at a scan rate of $10 \mathrm{mV} / \mathrm{s}$. It can be seen that different $\mathrm{NiCo}_{2} \mathrm{~S}_{4} / \mathrm{C}$ composite materials show varying degrees of pseudocapacitance material characteristics. NCS-h-COOH has the largest current intensity at the same scan rate and covers the largest area, so it has the highest specific capacity.

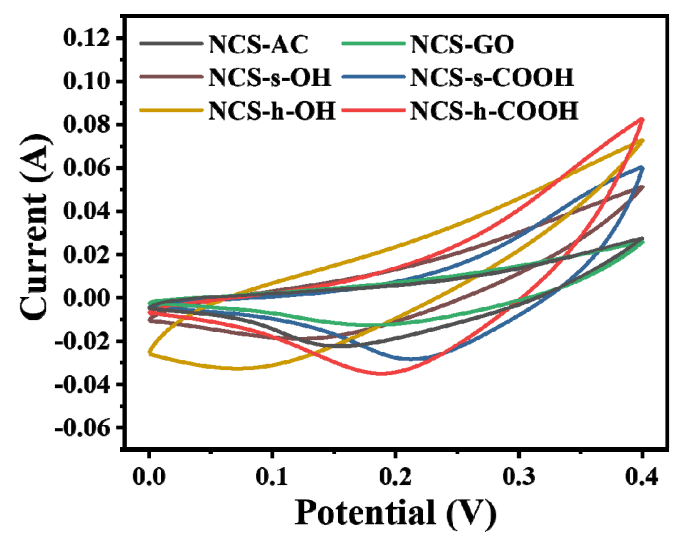

Fig. 3. The cyclic voltammetry curves of different $\mathrm{NiCo}_{2} \mathrm{~S}_{4} / \mathrm{C}$ composite materials

Fig. 4 shows the charge and discharge curves of different $\mathrm{NiCo}_{2} \mathrm{~S}_{4} / \mathrm{C}$ composite materials. Almost all the curves in the Fig. have a plateau in the voltage range of $0.15 \mathrm{~V}-0.23 \mathrm{~V}$, which corresponds to the potential of the redox peak in the cyclic voltammetry curve. Calculate the specific capacity under different charge and discharge current densities according to formula. The specific capacities of NCS-s-OH from 0.2 to $10 \mathrm{~A} / \mathrm{g}$ are 1135.04, 1254.48, 1176.47, 1077.99, 948.86, 684.51 F/g; NCS-s-COOH are 901.03, 1049.31, 1002.56, 843.82, 616.5, 540.75 F/g; NCS-h-OH are 1417.28, 1378.79, 1336.66, 1221.33, 1082.72, 911.24 F/g; NCS-h-COOH are 2055.04, 2038.74, 1939.12, 1788.57, 1673.13, $1627.58 \mathrm{~F} / \mathrm{g}$; NCS-AC from 0.2 to $20 \mathrm{~A} / \mathrm{g}$ are 879.09, 929.86, 915.09, 809.18, 461.19, $133.82 \mathrm{~F}$, respectively /g; NCS-GO from 0.2 to $20 \mathrm{~A} / \mathrm{g}$ are $737.77,857.14,874.75$, $825,813.449,603.1 \mathrm{~F} / \mathrm{g}$, respectively.
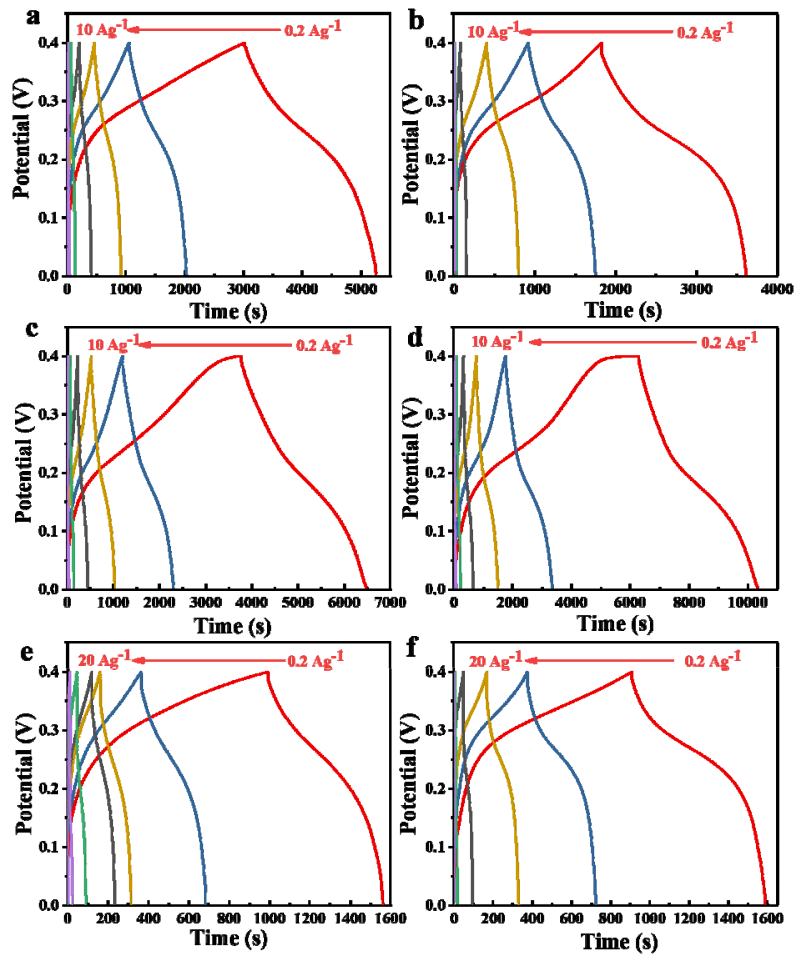

Fig. 4. The charge and discharge curves of different $\mathrm{NiCo}_{2} \mathrm{~S}_{4} / \mathrm{C}$ composite materials

Fig. 5a shows the curve of the specific capacity of different $\mathrm{NiCo}_{2} \mathrm{~S}_{4} / \mathrm{C}$ materials at various current densities. It shows that the composite carbon source does have the effect of increasing the specific capacity of this electrode material. It is extremely obvious in the composite CNT$\mathrm{h}-\mathrm{COOH}$ material, and the specific capacity of the composite CNT-h-COOH material reaches $2038.74 \mathrm{~F} / \mathrm{g}$. Fig. 5b shows the electrochemical impedance spectra of different $\mathrm{NiCo}_{2} \mathrm{~S}_{4} / \mathrm{C}$ composite materials. Fig. $5 \mathrm{c}$ is the partial enlarged view. In the high-frequency region, the impedance of all composite materials is very small, indicating that these materials have a high electron transfer rate in the high-frequency region. And it is particularly prominent in the NCS-h-COOH electrode material, with a Rs value of only about $0.25 \Omega$. In the low frequency region, except for activated carbon, the slope of the straight line is larger, so the material is conducive to the diffusion of ions. Among them, the slope of NCS$\mathrm{h}-\mathrm{COOH}$ is the largest, indicating the fastest ion diffusion and faster reaction. This can also be explained 
from the SEM spectrum of the material. It can be seen from the Fig. that the material is completely intertwined, so NCS-h- $\mathrm{COOH}$ electrode materials can have the highest conductivity.

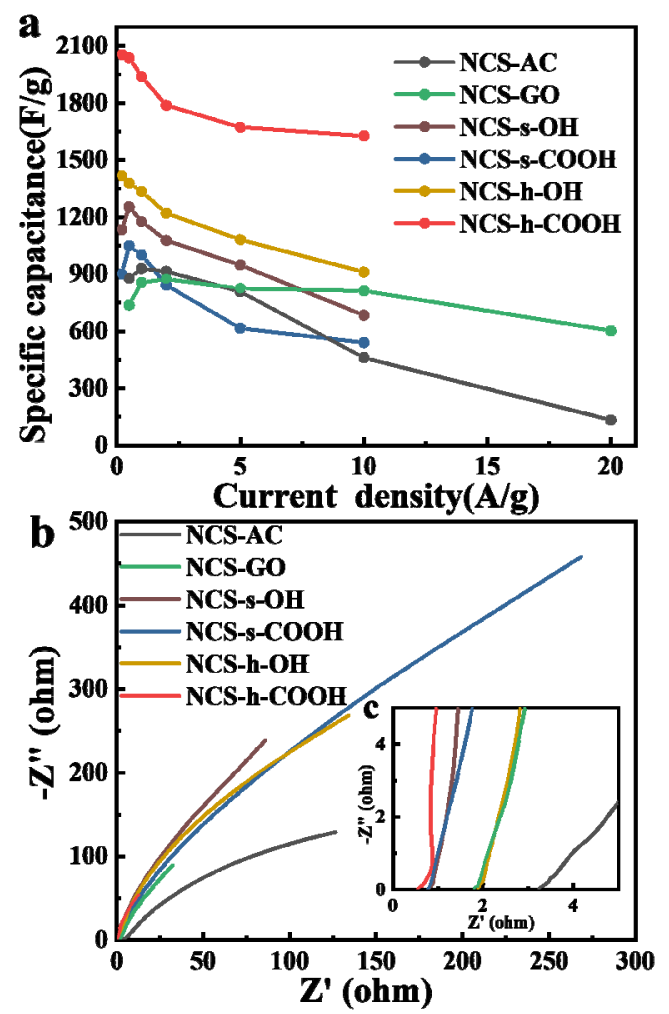

Fig. 5. The specific capacity at various current densities (a) and electrochemical impedance spectra of different $\mathrm{NiCo}_{2} \mathrm{~S}_{4} / \mathrm{C}$ materials.

\section{Conclusion}

The $\mathrm{NiCo}_{2} \mathrm{~S}_{4} / \mathrm{C}$ composite material was successfully prepared by a simple one-step hydrothermal method. The influence of the composite of different carbon sources on the material is explored. The carbon material has good conductivity, and the composition is beneficial to enhance the conductivity of the compound. After testing, analysis and comparison, the composite carbon source is beneficial to the improvement of the electrochemical performance of the material. Carbon composition increases the specific surface area of the material and provides more ion attachment points during the electrochemical process, which is more conducive to ion transportation and transfer, and increases the material's capacity. The conductivity of $\mathrm{NiCo}_{2} \mathrm{~S}_{4}$ is poor, and the composite carbon material can greatly improve the conductivity of the material. Electric double-layer capacitor materials can accept transferred ions faster than pseudocapacitor materials, so that $\mathrm{NiCo}_{2} \mathrm{~S}_{4}$ materials can better adapt to current intensity and have a longer charge and discharge platform. This discovery is of great significance to the research of pseudocapacitive materials and supercapacitors.

\section{Acknowledgements}

The authors gratefully acknowledge the support by Sichuan Science and Technology Program of 2018GZ0029, 2019YFH0002, 2020YFH0213, 2020YFG0357, 2020YFG0358, and 2019ZDZX0002, Science and Technology Commission Project of 18-16321-CH-002-003-01, and Central University Support plan of ZYGX2019Z022.

\section{References}

1. Z. Xu, C. Du, H. Yang, J. Huang, X. Zhang, J. Chen, Chem. Eng.J. 127871(2020)

2. X. Zhang, Q. Lu, H. Liu, K. Li, M. Wei, Appl. Surf. Sci. 528(2020)

3. Z. Wang, H. Jia, Y. Cai, C. Li, X. Zheng, H. Liang, J. Qi, J. Cao, J. Feng, Chem. Eng. J. 392(2020)

4. V. Ragupathi, P. Panigrahi, N. Ganapathi Subramaniam, Mater. Lett. 246 (2019)

5. Y. Xu, X. Gao, W. Chu, Q. Li, T. Li, C. Liang, Z. Lin, J. Mater. Chem. A, 4 (2016)

6. M. Idrees, S. Batool, J. Kong, Q. Zhuang, H. Liu, Q. Shao, N. Lu, Y. Feng, E. K. Wujcik, Q. Gao, T. Ding, R. Wei, Z. Guo, Electrochim. Acta, 296(2019)

7. Y.-Q. Cao, X. Qian, W. Zhang, M. Li, S.-S. Wang, D. Wu, A.-D. Li, Electrochim. Acta, 303(2019)

8. C. Tang, K. Zhao, Y. Tang, F. Li, Q. Meng, Electrochim. Acta, 375(2021)

9. D. Li, Y. Gong, C. Pan, Sci. Rep., 6(2016)

10. F. Wang, G. Li, Q. Zhou, J. Zheng, C. Yang, Q. Wang, Appl. Surf. Sci., 425(2017) 